\title{
Chest physiotherapy in preterm infants with lung diseases
}

\author{
Carmen Giannantonio ${ }^{1 \dagger}$, Patrizia Papacci ${ }^{1 \dagger}$, Roberta Ciarniello ${ }^{2 \dagger}$, Mikael Ghennet Tesfagabir ${ }^{1 *}$, Velia Purcaro ${ }^{1 \dagger}$, \\ Francesco $\mathrm{Cota}^{1 \dagger}$, Carla Maria Semeraro ${ }^{1 \dagger}$, Costantino Romagnoli ${ }^{1 \dagger}$
}

\begin{abstract}
Background: In neonatology the role of chest physiotherapy is still uncertain because of the controversial outcomes.

Methods: The aim of this study was to test the applicability in preterm infants of 'reflex rolling', from the Vojta method, in preterm neonates with lung pathology, with particular attention to the effects on blood gases and oxygen saturation, on the spontaneous breathing, on the onset of stress or pain. The study included 34 preterm newborns with mean gestational age of 30.5 (1.6) weeks - mean (DS) - and birth weight of 1430 (423) g - mean (DS) -, who suffered from hyaline membrane disease, under treatment with nasal CPAP (continuous positive airways pressure), or from pneumonia, under treatment with oxygen-therapy. The neonates underwent phase 1 of 'reflex rolling' according to Vojta method three times daily. Respiratory rate, $\mathrm{SatO}_{2}$, transcutaneous $\mathrm{PtcCO}_{2}$ e $\mathrm{PtcO}_{2}$ were monitored; in order to evaluate the onset of stress or pain following the stimulations, the NIPS score and the PIPP score were recorded; cerebral ultrasound scans were performed on postnatal days 1-3-5-7, and then weekly.

Results: In this population the first phase of Vojta's 'reflex rolling' caused an increase of $\mathrm{PtcO}_{2}$ and $\mathrm{SatO}_{2}$ values. No negative effects on $\mathrm{PtcCO}_{2}$ and respiratory rate were observed, NIPS and PIPP stress scores remained unmodified during the treatment; in no patient the intraventricular haemorrhage worsened in time and none of the infants developed periventricular leucomalacia.
\end{abstract}

Conclusions: Our experience, using the Vojta method, allows to affirm that this method is safe for preterm neonates, but further investigations are necessary to confirm its positive effects and to evaluate long-term respiratory outcomes.

\section{Background}

Chest physiotherapy (CPT) has been used to clear secretions, to reduce post-extubation atelectasis, to reduce the use of reintubation, and also to help lung ventilation in newborns with respiratory problems [1-3]. However, concerns about the safety of some forms of chest physiotherapy have been raised, especially for very low birth weight infants (VLBW), due to the risk of brain damage related to some CPT techniques [4].

The forms of CPT more commonly used during the neonatal period are active chest physiotherapy (tapping or vibration delivered on the chest) and non-active

\footnotetext{
*Correspondence: quinny_t@yahoo.it

† Contributed equally

'Department of Paediatrics, Division of Neonatology, "Sacro Cuore" Catholic University, Largo Francesco Vito 1, Rome, Italy

Full list of author information is available at the end of the article
}

techniques (e.g. positioning and suction alone), but caution is required also when interpreting the possible positive effects of these chest physiotherapy treatments [5-8].

With regard to the different $\mathrm{CPT}$ techniques and the controversial outcomes they yield, we decided to test the applicability in preterm infants of 'reflex rolling', from the Vojta method.

The Vojta method is a physical therapy, initially developed in the $1960 \mathrm{~s}$ for the treatment of children with or at risk of cerebral palsy. It is a program that employs isometric strengthening techniques through tactile stimulation, to encourage the development of normal movement patterns and therefore to improve respiration. The aim of this study was to evaluate the 'safety' of Vojta reflex stimulations in preterm neonates with lung diseases, investigating particularly the effects on blood

\section{(Ciomed Central}


gases and on oxygen saturation, the effects on spontaneous breathing and the presence of stress/pain.

\section{Methods}

The Ethical Committee of the Paediatrics Department approved the study protocol, and parents gave their informed consent.

\section{Subjects}

The study included preterm newborns with gestational age ranging from 28 to 34 weeks, admitted to the Neonatal Intensive Care Unit of "A.Gemelli" Hospital (Sacro Cuore Catholic University, Rome), from 1 January 2008, to 30 September 2008, who suffered from hyaline membrane disease, under treatment with NCPAP (nasal continuous positive airways pressure), or from pneumonia, who received oxygen-therapy.

Newborns with congenital malformations, asphyxia at time of birth, under treatment with neurotropic drugs, or with intraventricular haemorrhage $>2^{\text {nd }}$ grade according to Papile's classification, were excluded from the study [9].

All newborns breathed spontaneously, and were treated with:

1. Continuous positive pressure ventilation delivered by nasal cannula (maximum $\mathrm{CPAP}=6 \mathrm{~cm} \mathrm{H}_{2} \mathrm{O}$ and maximum $\mathrm{FiO}_{2}=0.40$ )

2. Oxygen-therapy with maximum $\mathrm{FiO}_{2}=0.40$

After birth, the newborns received citrate caffeine as prophylaxis of apnoea of prematurity. Antibiotic therapy was administered when diagnosis of pneumonia (clinical and radiological) was made.

\section{The 'reflex rolling' according to Vojta}

The neonates underwent phase 1 of reflex rolling according to Vojta. This manoeuvre does not require the newborn to be moved, but only a slight rotation of the head towards the side from which the stimulus is delivered. The starting position for performing the first phase of reflex rolling is the asymmetric supine position, with the limbs freely lying on the resting surface.

A digitopressure was exerted on the chest area, where the mammillary line crosses the insertion of the diaphragm, either at the level of the $6^{\text {th }}$ rib, or between the $5^{\text {th }}$ and the $6^{\text {th }}$, or between the $6^{\text {th }}$ and the $7^{\text {th }}$.

Each treatment consisted in delivering four stimuli, two to the left half of the chest (stimulations I and II) and two to the right half of the chest (stimulations III and IV). Each stimulus consisted of a slight pressure, progressively oriented in dorsal, medial and cranial directions, diagonally to the spine. The treatment was repeated three times a day, at time intervals of 0,2 and 4 hours.

\section{Monitoring and controls}

The tests performed were the following:

a. Respiratory rate (RR) and $\mathrm{SatO}_{2}$ were monitored by Hewlett-Packard HP monitor (Hewlett Packard M1205AOmni Care model, Andover, Germany);

b. Transcutaneous monitoring of $\mathrm{PtcCO}_{2}$ e $\mathrm{PtcO}_{2}$ by TINA (Radiometer Medical, Copenhagen, Denmark).

The tests were performed before the reflex stimulation, at the end of stimulation II, at the end of stimulation IV and at 5, 15, 25 minutes after the whole series of stimulations, during each of the three daily treatments.

c. Cerebral ultrasound scan on postnatal days 1-3-57, and weekly, using a color Doppler unit. (HewlettPackard Doppler 'IMAGE POINT')

\section{Monitoring of stress or pain}

In order to evaluate the onset of stress or pain following the stimulations, two pain and stress evaluation scales were adopted: the NIPS score (Neonatal Infant Pain Scale) and the PIPP (Premature Infant Pain Profile) Score $[10,11]$.

The NIPS scores were recorded before the reflex stimulation, at the end of the second stimulation, at the end of the fourth stimulation and at 5, 15, 25 minutes after the stimulation, during all three sessions. The PIPP scores were recorded only once in each session during stimulation.

\section{Statistical Analysis}

Continuous data are presented as mean \pm standard deviation. To compare each parameter at each time point, Repeated Measures One-way ANOVA with Bonferroni's Multiple Comparison Test was performed using GraphPad Prism version 4.00 for Windows (GraphPad Software, San Diego California USA, http:// www.graphpad.com). A score of $p<0.05$ was considered significant.

\section{Results}

Over the time of study, 60 neonates showed criteria of eligibility; 7 newborns with severe congenital malformation and 19 newborns who required mechanical ventilation were excluded. Therefore, the neonates included in the study were 34, 19 female and 15 male.

The gestational age of the newborns included in the study was 30.5 (1.6) weeks -mean (DS) - and the neonatal weight was 1430 (423) g - mean (DS) -.

We studied the effects of the application of 'reflex rolling' during the first week of life and after the first week of life. Therefore, two groups of newborns were observed (Table 1): 
Table 1 Clinical Characteristics of the two study groups

\begin{tabular}{ccc}
\hline & Group 1 & Group 2 \\
\hline Number of patients & 21 & 13 \\
\hline Gestational Age (weeks) mean \pm SD & $30.3 \pm 1.0$ & $30.8 \pm 2.3$ \\
\hline $\begin{array}{c}\text { Birth Weight }(\mathrm{g}) \text { mean } \pm \mathrm{SD} \\
\text { (range) }\end{array}$ & $1340 \pm 180$ & $1575 \pm 635$ \\
$(1010-1640)$ & $(565-2480)$ \\
\hline Sex ratio (male/female) & 1.1 & 0.44 \\
\hline $\begin{array}{c}\text { Postnatal Age (days) mean } \pm \mathrm{SD} \\
(\text { range) }\end{array}$ & $6 \pm 1$ & $10.6 \pm 3.5$ \\
$(2-7)$ & $(8-20)$ \\
\hline IVH <3 grade $\left(\mathrm{n}^{\circ}\right)$ & 2 & 4 \\
\hline $\mathbf{C L D} \mathrm{n}^{\circ}(\%)$ & $3(14,3)$ & $3(23,1)$ \\
\hline
\end{tabular}

GROUP 1: 21 newborns with hyaline membrane disease during the first week of life. All newborns were treated with NCPAP.

GROUP 2: 13 newborns with a respiratory disease persisting after the first week of life, who were spontaneously breathing and on oxygen-therapy.

In any case, the IVH (intraventricular haemorrhage) diagnosis was made during the infant's first day of life; in no patient the intraventricular haemorrhage worsened in time. None of the infants we observed developed periventricular leucomalacia.

\section{Monitoring of blood gases and respiratory rate}

In group $1, \mathrm{PtcO}_{2}$ was found to be significantly different across the time points $(\mathrm{p}<0.0001)$; post-hoc analysis according to Bonferroni showed a significant difference $(\mathrm{p}<0.05)$ among the mean values of $\mathrm{pO}_{2}$ : before the stimulation and at 5, 15' e 25'; at the end of stimulation II and at 5, $15^{\prime}$ e $25^{\prime}$; at the end of stimulation IV and at $15^{\prime}$ and $25^{\prime}$. In a similar way, $\mathrm{SatO}_{2}$ was found to be significantly different across the time points $(\mathrm{p}<0.001)$; post-hoc analysis according to Bonferroni showed a significant difference $(\mathrm{p}<0.05)$ among the mean values of $\mathrm{SatO}_{2}$ : before the stimulation and at 5'; at the end of stimulation II and at $15^{\prime}$ and $25^{\prime}$. No statistically significant difference was found for $\mathrm{ptcCO}_{2}$. No increase in RR was recorded; therefore, it is possible that the improved oxygenation induced by this method may be due to an increased tidal volume. (Table 2).
In group 2, $\mathrm{PtcO}_{2}$ was found to be significantly different across the time points $(\mathrm{p}<0.01)$; post-hoc analysis according to Bonferroni showed a significant difference $(\mathrm{p}<0.05)$ among the mean values of $\mathrm{pO}_{2}$ : before the stimulation and at 25'; at the end of stimulation II and at $25^{\prime}$; at the end of stimulation IV and at $25^{\prime}$. SatO $\mathrm{S}_{2}$ was found to be significantly different across the time points ( $\mathrm{p}<0.05)$; but Bonferroni's multiple comparison test did not show any significant difference among individual evaluations. No statistically significant difference was found for $\mathrm{ptcCO}_{2}$, nor for RR (Table 3).

\section{Monitoring of stress/pain}

The NIPS scores for the two study groups did not show pain nor stress signs during stimulation, in any of the daily settings. Moreover, the PIPP scores showed no stress. The values found in group l were: 6.1 (1.9) -mean (SD) - with the first recording; 6.0 (2.0) with the second recording; 6.2 (1.5) with the third recording and in group 2 they were 6.3 (1.6) with the first recording; 6.2 (1.7) with the second recording and 6.4 (1.8) with the third recording.

\section{Discussion}

In neonatology, respiratory physiotherapy is still controversial [5].

In treating neonates, the most renowned methods are mechanical techniques such as percussion and vibrations, which represent the so-called active respiratory physiotherapy (ARP), postural drainage, tracheal aspiration, elicitation of the cough reflex, respiratory modifications induced by means of posture.

The specialized literature concerning neonates mainly sets its focus on active respiratory physiotherapy and on the specific aspect of preventing post-extubation atelectasis.

With regard to the prevention of post-extubation atelectasis, the strong doubts concerning the actual utility of active respiratory physiotherapy seem to be confirmed; in fact, there is no evidence of a clear benefit in terms of a decreased rate of post-extubation lobar collapse $[5-7,12,13]$. Besides the scarce benefits, some authors have suggested that ARP might entail the risk of a neurologic damage, especially in neonates whose

Table 2 Blood gases, $\mathrm{SatO}_{2}$ and respiratory rate (RR) in group 1

\begin{tabular}{|c|c|c|c|c|c|c|}
\hline & pre stim. & end II stim. & end IV stim & $5 \mathrm{~min}$ & $15 \mathrm{~min}$ & $25 \mathrm{~min}$ \\
\hline $\begin{array}{l}\mathrm{PtcO}_{2}(\mathrm{mmHg}) \\
\text { Mean }( \pm \mathrm{SD})\end{array}$ & $61.7(12.9)$ & $61.3(12.9)$ & $63.2(12.7)$ & 68.6 (13.7) & 70.9 (13.9) & $73.1(13.6$ \\
\hline $\begin{array}{l}\text { SatO }_{2}(\%) \\
\text { Mean }( \pm \text { SD) }\end{array}$ & $92.2(3.9)$ & $92.0(2.8)$ & $92.5(3.8)$ & 93.6 (3.3) & $94.3(3.1)$ & $94.0(3.2)$ \\
\hline $\begin{array}{l}\mathrm{PtcCO}_{2}(\mathrm{mmHg}) \\
\text { Mean }( \pm \mathrm{SD})\end{array}$ & $42.1(6.4)$ & $42.2(7.2)$ & $42.6(7.7)$ & $43.0(6.7)$ & $43.6(6.4)$ & $44.2(6.9)$ \\
\hline $\begin{array}{l}\text { RR }(b / \text { min }) \\
\text { Mean }( \pm \text { SD) }\end{array}$ & $42(10)$ & $48(13)$ & $47(15)$ & $45(10)$ & $45(11)$ & $46(12)$ \\
\hline
\end{tabular}


Table 3 Blood gases, $\mathrm{SatO}_{2}$ and respiratory rate (RR) in group 2

\begin{tabular}{|c|c|c|c|c|c|c|}
\hline & pre stim. & end II stim. & end IV stim & $5 \mathrm{~min}$ & $15 \mathrm{~min}$ & $25 \mathrm{~min}$ \\
\hline $\begin{array}{l}\mathrm{PtcO}_{2}(\mathrm{mmHg}) \\
\text { Mean }( \pm \mathrm{SD})\end{array}$ & $65.8(12.9)$ & $63.9(9.6)$ & $64.1(11.6)$ & $66.8(10.8)$ & $69.6(14.5)$ & $73.6(15.0)$ \\
\hline $\begin{array}{l}\text { SatO }_{2}(\%) \\
\text { Mean }( \pm \text { SD) }\end{array}$ & $94.7(3.0)$ & $95.6(3.2)$ & $95.7(4.0)$ & $96.8(2.8)$ & $97.4(2.6)$ & $97.5(2.9)$ \\
\hline $\begin{array}{l}\operatorname{PtcCO}_{2}(\mathrm{mmHg}) \\
\text { Mean }( \pm \mathrm{SD})\end{array}$ & 45.9 (5.9) & $45.8(6.2)$ & $45.5(5.2)$ & $44.9(4.9)$ & $44.8(4.1)$ & $44.9(4.0)$ \\
\hline $\begin{array}{l}\text { RR }(b / \text { min }) \\
\text { Mean }( \pm \text { SD) }\end{array}$ & $46(15)$ & $41(11)$ & $42(16)$ & $41(12)$ & 45 (18) & 47 (13) \\
\hline
\end{tabular}

weight is $<1500$ grams, a risk which other studies did not confirm [4,8,13-18].

It is not surprising; however, that active respiratory physiotherapy might prove to be an invasive technique for preterm newborns. In fact, it has been stressed that ventilated patients may show irritability, an increased consumption of oxygen, an increased heart rate and arterial blood pressure, a higher rate of gastro-oesophageal reflux and, what represents a high risk for preterm newborns, an increased intracranial pressure $[19,20]$.

In any case, active respiratory physiotherapy and particularly vibrations and percussion are unsuitable for VLBW neonates, due to their physical features; in fact, in these patients the anatomical and physiological features of the ribcage subdue and cancel the effect of the aforesaid techniques, which nevertheless maintain their effectiveness in childhood and in adult age.

Therefore, non-active respiratory physiotherapy (i.e. postural therapy and postural drainage) seems to be the only respiratory physiotherapic technique available for VLBW neonates.

In 1967 Vàclav Vojta developed and made public the reflex rolling model, defining the chest as a crucial area. By stimulating the chest of a child suffering from athetosis and relapsing episodes of pneumonia and atelectasia unaffected by other active respiratory physiotherapic treatments, Vojta noticed a global reaction, consisting of a rotation of the head with flexion of the lower limbs and rotation of the pelvis, opening of the hands and, what is most important, an increase in depth of costal respiration, with an expansion of the ribcage [21].

The importance of these stimulations, especially if repeated, lies in the fact that the afferences due to induced physiologic muscle activity are imprinted in the central nervous system (CNS) and memorized. The CNS is set in an activated state, and the duration of such activation persists for at least half an hour after the stimulation has ended.

Our study aimed at evaluating the use of 'reflex rolling' in preterm neonates suffering from respiratory diseases. In the neonates we studied, the first phase of
Vojta's 'reflex rolling' caused an increase of $\mathrm{PtcO}_{2}$ and $\mathrm{SatO}_{2}$ values, showing a positive action on oxygenation.

No negative effects on $\mathrm{PtcCO}_{2}$ were observed, as these values remained constant over the treatment period, and within the normal range. A further confirmation of this technique's safety came from the negative results of the NIPS e PIPP stress scores, which remained substantially unmodified over the treatment.

The positive results obtained should be followed by a further investigation concerning the efficacy of the 'reflex rolling' technique in preterm newborns, by means of a randomized controlled study. The positive effects may be confirmed by the evaluation of respiratory functionality tests and by long-term respiratory outcomes.

\section{Conclusion}

Although the role of CPT in neonates with respiratory diseases remains debated and needs further evaluation, our experience concerning the use of Vojta's method provides a different perspective and takes again into consideration respiratory physiotherapy as a resource for the treatment of neonatal lung diseases. Studies performed on larger series of patients may be able to definitively confirm the effectiveness of Vojta's method as a suitable treatment for neonates, particularly in order to provide a support for all other therapeutic measures based on the use of drugs and ventilation.

\section{Author details}

'Department of Paediatrics, Division of Neonatology, "Sacro Cuore" Catholic University, Largo Francesco Vito 1, Rome, Italy. 'Department of Physiatrics, Service of Physical Medicine and Rehabilitation, "Sacro Cuore" Catholic University, Largo Francesco Vito 1, Rome, Italy.

\section{Authors' contributions}

CG: drafted the manuscript, PP: designed and coordinated the study, RC: performed Vojta method on every subject, MGT: acquisition and collection of data, VP: acquisition and collection of data, FC: participated in the design of the study and performed the statistical analysis, CMS: analysis and interpretation of the data, CR: drafted the manuscript and revised it. All authors read and approved the final manuscript.

\section{Competing interests}

The authors declare that they have no competing interests. 


\section{References}

1. Finer NN, Boyd J: Chest physiotherapy in the neonate: a controlled study. Pediatrics 1978, 61:282-285.

2. Etches PC, Scott B: Chest physiotherapy in the newborn: effects on secretions removed. Pediatrics 1978, 62(5):713-715.

3. Lewis $J A$, Lacey $J L$, Henderson-Smart $D J$ J: A review of chest physiotherapy in neonatal intensive care units in Australia. J Paediatr Child Health 1992, 28:297-300.

4. Harding JE, Miles FKI, Becroft DMO, Allen BC, Knight DB: Chest physiotherapy may be associated with brain damage in extremely premature infants. J Pediatr 1998, 132:440-444.

5. Flenady VJ, Gray PH: Chest physiotherapy for preventing morbidity in babies being extubated from mechanical ventilation. Cochrane Database Syst Rev 2002, 2: CD000283.

6. Bagley CE, Gray PH, Tudehope DI, Flenady V, Shearman AD, Lamont A: Routine neonatal postextubation chest physiotherapy: a randomized controlled trial. J Paediatr Child Health 2005, 41(11):592-7.

7. Halliday $\mathrm{HL}$ : What interventions facilitate weaning from the ventilator? A review of the evidence from systematic reviews. Paediatr Respir Rev 2004, 5(Suppl A):S347-52.

8. Gray PH, Flenady VJ, Blackwell L: Potential risks of chest physiotherapy in preterm infants. J Pediatr 1999, 135(1):131.

9. Papile $L A$, Burstein J, Burstein $R$, Koffler $H$ : Incidence and evolution of subependymal and intraventricular haemorrhage: a study of infants with birth weights less than 1,500 gr. J Pediatr 1978, 92(4):529-34.

10. Lawrence J, Alcock D, McGrath P, Kay J, MacMurray SB, Dulberg C: The development of a tool to assess neonatal pain. Neonat Netw 1993, 12:59-66.

11. Stevens $B$, Johnston $C$, Petryshen $P$, Taddio A: Premature infant pain profile: development and initial validation. Clin J Pain 1996, 12:13-22.

12. Al-Alaiyan $S$, Dyer $D$, Khan B: Chest physiotherapy and post-extubation atelectasis in infants. Pediatr Pulmonol 1996, 21:227-230.

13. Bloomfield FH, Teele RL, Voss M, Knight DB, Harding JE: The role of neonatal chest physiotherapy in preventing postextubation atelectasis. Journal of Pediatrics 1998, 133(2):269-271.

14. Raval D, Yeh TF, Mora A, Cuevas D, Pyati S, Pildes RS: Chest physiotherapy in preterm infants with RDS in the first 24 hours of life. J Perinatol 1987, 7(4):301-4.

15. Cross JH, Harrison CJ, Preston PR, Rushton DI, Newell SJ, Morgan ME, Durbin GM: Postnatal encephaloclastic porencephaly-a new lesion? Arch Dis Child 1992, 67(3):307-11.

16. Vincon C: Potential risks of chest physiotherapy in preterm infants. $J$ Pediatr 1999, 135(1):131-2.

17. Knight DB, Bevan CJ, Harding JE, Teele RL, Kuschel CA, Battin MR, Rowley RS: Chest physiotherapy and porencephalic brain lesions in very preterm infants. J Paediatr Child Health 2001, 37(6):554-8.

18. Beeby PJ, Henderson-Smart DJ, Lacey JL, Rieger I: Short- and long-term neurological outcomes following neonatal chest physiotherapy. J Pediatr Child Health 1998, 34:60-62.

19. Fox W, Schwartz J, Shaffer T: Pulmonary physiotherapy in neonates: physiological changes and respiratory management. J Pediatr 1978, 92:977-981.

20. Krause MF, Hoehn T: Chest physiotherapy in mechanically ventilated children. A review. Crit Care Med 2000, 28(5):1648-1651.

21. Vojta V: Reflex rotation as a pathway to human locomotion. $Z$ Orthop Ihre Grenzgeb 1970, 108(3):446-52.

doi:10.1186/1824-7288-36-65

Cite this article as: Giannantonio et al:: Chest physiotherapy in preterm infants with lung diseases. Italian Journal of Pediatrics 2010 36:65.

\section{Submit your next manuscript to BioMed Central and take full advantage of:}

- Convenient online submission

- Thorough peer review

- No space constraints or color figure charges

- Immediate publication on acceptance

- Inclusion in PubMed, CAS, Scopus and Google Scholar

- Research which is freely available for redistribution

Submit your manuscript at www.biomedcentral.com/submit
C Biomed Central 